The Dhaka University Journal of Linguistics: Vol. 1 No.2 August, 2008 Page : 45-66, Published on August 2009 (C) Registrar, Dhaka University ISSN-2075-3098

\section{Semantic values in Translating from English to Bangla}

\section{Mohammad Daniul Huq}

Professor,Department of Bengali, Jahangirnagar University

\begin{abstract}
Translating from other languages to Bangla is confronted with multiple factors. Hindrance seems hidden within the system, or to say, with the applied discipline of this very language, pivot of all may be examined as the transference of semantic values from SL to TL. This paper tries to depict the nature of Bangla while examining the peripheral aspects related to a meaningful and ostensive translated version. Discussion with appropriate examples forms the main burden of the paper. Concerns of translation theories vs. problems will ultimately be taken up exposing Bangla in particular trivial examples. It is expected that, subjectivity and individual traits of an author will find expression in style register.
\end{abstract}

Translating into Bangla have been going on from the middle age from Source Language of Sanskrit, Hindi, Persian, Arabic and the other European languages, but English being the prime amongst those. We would therefore gloss mainly depending on English examples that the author believes will facilitate the international readers in better understanding.

This article is based on the identical theme of the author's earlier write-up published in The Jahangirnagar Review, Part C, Vol. VI. Considering the nature of the subject matter and the fact that there is a dearth of such initiative on the translation related renderings, the present article is published here as revised version of his previous one. --The Editor.

\section{Introduction}

Translation from English to Bengali ('Bangla' hereafter), dates back as early as the late $18^{\text {th }}$ century, but the real forerunners in translation from English to Bangla were the Christian Missionaries of Serampore starting with Bangla translation of the New Testament (Feb, 1801). During the early $19^{\text {th }}$ century the scholars of Fort William College in Calcutta came out with quite a number of Bangla prose translations that fortified their Bangla translation. An overall colloquial easy language style was also developed alongside. The new Bangla prose had to give special attention to syntax, because syntax was the primary difficulty among the writers of that period. Incidentally, syntax pattern of early translation often adhered to English that was contrary to Bangla language style.

In pioneering the task the early Bangla translators/writers were confronted with many difficulties in their experimental efforts to shape prose into a suitable medium of literary expression. They indulged in experimentation of various kinds, prime of which was imitating grammatical features of English. Translation of lexical items used to be one of the convenient techniques of translation. It was evidently so because there was no established literary norms of early Bangla prose, for which it took quite a while for the translators to handle the diversities of these two languages. Bangla gained its real momentum in the hands of some celebrities as a result of which the mid-nineteenth and early-twentieth centuries saw the growth of a rich literary trend of Bangla -- a major portion of which is again from English. Incidentally, translation from English till this day is one of the inevitable on-going processes resulting in an enormous intake on Bangla in several different disciplines and in all diversities.

\section{Strategies}

Before entering into the deep of the linguistic analysis we can check some of the renowned translators' strategies that were acclaimed well by the readers in general. This has been so for the fact that, literary translations are of special consideration.

Vol. 1 No.2 August, 2008 
For translating into English from other languages Ezra Pound has spoken of a kind of parallelism. Michael Modhusudan Dutt in Bangla from his Greek and Latin sources has transformed the images and created parallel pattern in Bangla. (The famous modern Greek poet George Seferis who has translated The Wasteland has also translated E. Pound's Cantos into modern Greek. It was possible because Pound's Sources for his Cantos are Greek and Latin history and mythology. Seferis was able to transfer those images into Modern Greek without creating any parallelism. In the case of Modhushudan who was greatly influenced by ancient Latin and Greek epics, a parallelism had to be created. Modhusudan used Indian mythology in place of Greek and Latin, but selected those images in such a way that they remained parallel to the original images). Nevertheless, one cannot possibly do justice like in translating the same way Pound's "Cantos" in Bangla. Nonetheless, Walt Whitman's "Pioneer O Pioneer" pleasantly fits into Kazi Nazrul Islam's “Aogro Pathik Hay Shenadol..." for prosody and the theme. Vidyasagar in Bangla, intricated to other linguistic strategy of alliteration. He was the one to introduce the use of separate adjective in Bangla and transforming adverbs from English for his purposes.

\section{Onset of the two languages problem}

Although historically English and Bangla belong to the same great family tree of Indo-European languages, their distant relationship can hardly be traced back. Although both the languages are classified as inflectional languages, the major differences between these two, however, are syntactical and phonological. Phonologically speaking, the Bangla sound inventory is able to accommodate English with relative facility (Huq,1990), but English syntax awfully continues to be the core for the concern for Bangalee learners and translators. In the early days the new Bangla prose had to give special attention to syntax, because syntax was the primary difficulty among the writers of that period. Incidentally, syntax pattern of early translation often adhered to English that was contrary to Bangla language style.
Basic structures of these two languages are quite different in their stylistics and/or grammar. While English follow the Subject+Verb+Object pattern, Bangla has the word order of Subject+Object+Verb in general. Although Bangla is more "word order free" than English, the different auxiliary verbs and modals, tenses and syntactic interpretive rules of English make it difficult for a Bangla writer to cope with this language.

However, there are some advantages in Bangla too. By virtue of its linguistic versatility, Bangla has a tremendous ability to absorb the richness of other languages, which has made it probably the richest of languages of the Indian subcontinent. Bangla was influenced historically, by several different languages (both European and nonEuropean) before English became the medium of interaction in the sub-continent. As early as the $5^{\text {th }}$ century Tibeto-Burmese people inhabited the region which was named "Banga" (Bangal) and is now Bangladesh. Before the British finally established their suzerainty over this region, Turks, Afghans, the Mughals, the Arabs and the Portuguese had already visited this land and some of them had also settled here. When the Muslim rulers directed their conquest to Bengal at the turn of the $13^{\text {th }}$ century, they introduced Faarsi as the court-language but patronized Bangla most favourably as the language of art, literature and daily life.

Bangla had already adopted many of the linguistic characteristics of the Old Indo-Aryan language i.e. Sanskrit (including grammar, lexical items, alphabets, phonetic system) and from non-Aryan languages of the sub-continent. 'Tadbhaba' words (derived from Sanskrit) were used in abundance from the beginning of the $19^{\text {th }}$ century. Though Bangla had a rich linguistic tradition, the Western Missionaries began to improve Bangla prose through translation up to a level suitable for preaching Christianity. Bangla prose however was 
subsequently fortified by interaction between Bengal and Western civilization, both culturally and linguistically.

\section{Of translation : Theories vs. Problems}

Problems of translating have been discussed and identified by scholars from several different angles of a number of languages and cultural setups.

In the $18^{\text {th }}$ century there had been some studies on the theory and practice of translation in English ${ }^{\mathbf{1}}$. In mid twentieth century I.A. Richards (1953) remarked, "Translation probably is the most complex type of event yet produced in the evolution of the cosmos". The magnitude of the task of translating from one language to another, which led to such statement, holds good till this day of the nineties.

Theoretically speaking, translation involves the rendering of Source Language (SL) text into the Target Language (TL) so as to ensure that surface meaning of the two will be preserved as closely as possible, but not so closely that the TL on understanding the source syntax of the language (SL) and on using translation as a means of demonstrating that understanding. But in modern view this may be interpreted as some kind of restricted concept.

Two things must be distinguished clearly : the product (the end result of the translation process) and the process itself. Because the translations are so diverse, the text so different, and receptors so varied that in order to be a translator one is bound to be speculative in formulation of principles and practices of translation. But the translator must know both the SL and TL and he should be familiar with the subject matter, let alone to have some mastery over the receptor language.

There is little agreement on how and to what extent the science of language or even the knowledge of language structure can and should be applied. For a better understanding, it is essential to review the relations between the source, the message, and the receptors in the communication process.

For our purpose we put four strategies of translation that can be considered (Casagrande, 1954)

a. Pragmatic translation - translation of message in accuracy of information. Example : translating some technical documents.

b. Aesthetic-poetic translation - the translator takes account of the aesthetic form used by the original author. Example : translating literary pieces.

c. Ethnographic translation - to explicate the cultural context of the source and second language versions. Example : translation of Bible or some world classics.

d. Linguistic translation - concerns equivalent meanings of the constituent morphemes of the second language and with grammatical form. (Example is not mentioned here, but please notice forth coming discussions)

Our present discussion is related to all the above four but it is inclined more to the last one. Eugene E. Nida (1964) elaborates this in forwarding three-part division of approaches to translation, namely the philological, the linguistic and the sociolinguistic.

Saussure, the pivotal figure of the structural approach to language tried to explain the concept of translation as " The structural relationship between the signified (signifie') of concept of a word and the signifier (signifiant) of the sound-image made by the particular word constitutes the linguistic sign of the word." (Saussure,1974) 
Whatever may be the suggested concept of explanation towards the feature of translation, problem of linguistic translation in the case of English to Bangla remains unique in nature. What the Prague Linguistic Circle and its disciples in the early twentieth century established remains good for Bangla translators in this last part of the century. They held that translation is one of the most difficult tasks that a writer can take upon himself : because translation involves far more than a working acquaintance with two languages (SL and TL ).

By the above reference it follows that a translation is not a monistic composition, but an inter-penetration and conglomerate of two structures. On the one hand, there is the semantic content and the formal contour of the original, on the other hand, the entire system of aesthetic features bound up with the language of the translation. Catford (1956) thus tackled the problem of linguistic translatability, with reference to two processes in his short study and identified that in translation there is substitution of TL meanings for SL meanings : not transference of TL meanings SL. In transference there is an implantation of SL meanings into the TL text.

(These two processes must be clearly differentiated in any theory of translation.)

\section{Of loss and untranslatiability}

One of the problems of translating from English to Bangla should better be termed as untranslatability which as such can straightly be of three types : Cultural, Geographical and Linguistic.

Problems of loss in translation include difficulties encountered by the translator when faced with terms or concepts in the SL that do not exist in TL.

The large number of terms in English for light and water, in French for types of bread or in Arabic aspects of camel behaviour, all may present the translator with one level or other of an untranslatable problem (Saussure, 1974). In addition to the lexical problems, there are, of course, languages that do not have tense systems or concepts of time that do not correspond to TL. When the translator encounters such difficulties, the whole issue of the translatability of text is raised (Catford, 1956).

\subsection{Cultural consideration}

Despite the fact that English as the language of the ruling class and as a language of the state affairs has been in close contact with the Bengalee people culturally, this language is not generally close to the indigenous/native speakers. English language itself became all the more culturally complex from the time of Charles II when FrenchLatin words and culture made ways into England. The difference in the cultural backgrounds of English and Bangla makes it difficult to translate ideas and situational aspect according to proper cultural setting. For example, expressions in English like "Hats off to your Lordship" or "Hats off to the warriors ....." cannot be culturally translated properly into Bangla, because this kind of expression is typically conditioned by the cultural bindings of the English society and their heritage. It is culturally untranslatable because of the absence in the TL culture of a relevant situational feature of the SL text. Besides, interlingual communication in such cases implies some differences in cultural setting, with accompanying diversities in value systems, conceptual presuppositions, and even historical antecedents.

\subsection{Geographical context}

We can take, for example, expression used in England or North America like :

"May be yes may be no

May be rain may be snow" 
This is some what impossible to translate into satisfactory Bangla expression due to the fact that rain coupled with snow, and only rain or only snow are quite unique phenomena that are geographically conditioned in those two countries, and that are different from Bangla speaking regions. The underlying principles to be followed for determining here the adequacy of translation are largely sociolinguistic. Here, 'situation context' for evaluating the appropriateness of translation may be viewed as an aspect of 'communication'. [To be taken up again at the end of our discussion.]

\subsection{Linguistic dilemmas}

On the linguistic level, it occurs when there is no lexical or syntactical substitute in the TL for SL item. For example, English "damn you" cannot be linguistically translated into Bangla, because such expression involves structures and semantic equivalence that do not exist in Bangla. A sense-translation may be "P过 w"/ chulae jaa/ or "Runatg h"/ jahanname jaa/, back-translation of which will end as : 'you go to hell'.

More examples can be given ${ }^{2}$. In the book Alice in wonderland by Lewis Carol there is a sentence like "we used to call her tortoise, because she taught us" (Jakobson, 1959). This kind of expression is easily understood by English speaking people with its fun or Pun in the word 'tortoise' since the word is pronounced [ $\mathrm{t} o: \mathrm{t} \mathrm{O} \mathrm{s}]$. But how would a Bengalee writer translate the objective of this particular situation? Linguistics demonstrates that translation is a dialectic process that can be accomplished with relative success. Translation and linguistics encompass the comparative arrangement of linguistic element between the SL and TL texts with regard to phonemic, morphemic, lexical, syntagmatic and syntactic levels. Problems of linguistic equivalence, language-bound meaning, linguistic untranslatability etc. are also under this domain. If linguistic approach is that: translation means transfer of 'meaning' contained in one set of language signs into another set of language signs through competent use of dictionary and grammar, then it follows that it belongs most properly to semiotics -- although translation has a central core of linguistic activity. In the two languages of our discussion, no two texts codify exactly the same area of experience, yet a translator, like a grammarian and a lexicographer, is a student of meaning and, like them has to make use of a large variety of empirical things. This is all the more true for a translator from English to a different language, the Bangla, when he has to ensure context as well as actual sense/message for his readers.

\section{Problems for Bangla in particular}

From a rough estimate it may be stated that the major portion of translation from English to Bengla has been "literary" type of translation (vide: b, and also c. in Sec. 2.0. for the type we indicate and the concluding part of this article). Old theoreticians hold that "all poetic arts are technically untranslatable" (Jakobson, 1959). While translation proper reflects the process of transfer from SL to $\mathrm{TL}$, there is ordinarily no full equivalence for translation - since each unit contains within itself a set of non-transferable associations and connotations. This problem is optimally prime for a Bangla translator while translating from English. Experience is largely determined by the language habits of the Bangla-speaking community. And therefore each separate 'expression' represented is structured as separate reality. Lila Ray, a renowned professional translator from English to Bangla, described the kind of careful analysis needed for successful Bangla translation of literary works/forms (Ray,1976). She detailed the steps taken in translating, which include some specific techniques devised on the consideration that is mentioned as : "no two languages, no two texts, codify exactly the same area of experience". Thus when concern for translating from particular SL to TL has to be language specific, in Bangla-context, translator must deal with such added dimensions as the more frequent use of metaphor, irony, alliteration, onomatopoeia, and so forth to achieve the desired purpose. [The most stake example of the absence of such literary devices is in technical materials though.] 
As an experienced translator Mrs. Ray aims "to give the sound, the sense, and the feel of a text in a language other than that in which it is originally written" (Roy,1976:20 ). For the sound, she studies the physical components of the text; and to get the feel of the text studies the author's use of syntax. This is described as "Surface Analysis" while "Analysis in Depth" is given for full cognition and contentedness.

\subsection{Sound : the physical components}

To tackle equivalent words with rare of common letters, a contrastive analysis may be done by the translator as a working strategy. Bangla can linguistically give almost more than half of English phonemes (Huq, 1990). Hence vowels and consonants can be provided for with acceptable approximation. Lila Ray (1976) has demonstrated the usefulness of this kind of analysis in the translation of nursery rhymes in particular. She showed one line from English as follows :

\section{"Hichory dickory doch"}

i o y i o y o : $: 7$ vowels : pattern of recurrence to be noted.

h ek r ck r dk $\quad: 8$ consonants : pattern to be noted.

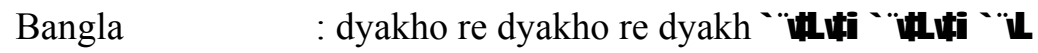

ya o e ya o e ya $: 7$ vowels (similarity of pattern to be noted)

$\mathrm{d}$ kh rd kh rd kh : 8 consonants

In a situation where poetic/dramatic flavours are to be conveyed to TL the shades of 'sound attributes' are taken care of. Since vowels and consonants both have pitch contours, so have words, changes in level of pitch have to be noted and imitated. Pitch is affected by the length and duration of vowels and consonants, and their position in the text. In accordance to Bangla's four pitch contours translation from English may have (a) high - rising - falling (b) high - rising (c) low - falling - rising and (d) low - rising - falling pitches.

\subsection{Morphemes : the working units}

The English morphemes (vocabularies) have the advantage of being used in multiple and diverse semantic values. On the contrary Bangla vocabularies generally are of precise semantic value with limited diversities. This contrast puts a translator of Bangla in a precarious position in choosing a suitable vocabulary for TL. For examples,

1. "Run" in English may be used at least in 12 situations with different semantic values; parallel Bangla word for 'run' as verb or noun is “乎”/douR/which is hardly used for more than 3 different meanings.

2. "Trade" in English may have a semantic use like-'rival factions trade gun firing'. In Bangla for the item 'trade' there will be one rendering /banijjyo/ "ewar." with an interpretation of commercial act.

Vocabularies for given text are useful compilation. The same word is expected to be translated by the same equivalent as often as it recurs; so should phrases of patterns of Bangla inflection. A Bangla translator will find that an account of such vocabularies greatly simplify his job.

\subsubsection{Words or Terms}

(Linguistic/extra-linguistic considerations)

Bangla translators and writers of specialized subjects, people responsible for making terminologies that are widely usable in translation do not always have a clear conception of semantic values or of using grammatical norm in coining new words or terms to the utmost appropriateness. They hold that most of the English terms express certain connotation, clearly and vividly, which a parallel Bangla term will lack. Some reservations work as the result of ignorance and lack of knowledge about the nature, versatility and power of assimilation by Bangla. Because of Bangla's inherent 
literary nature some translated terms for English are literally inclined instead of expressing the technical aspects of the subject.

\section{Examples :-}

English term

1. heart

Translated wrongly

Semantically correct

heart hridoy bodol/ "exchange of

transplantation heart as in love-affair"

üno ingthrohritpindo shongjojan/

2. economic function

\section{A}

/arthonoitic bichitra/

"economic varieties"
A $K K$ K

/arthonoitic karmadhara/
In some cases even such translated terms create the danger of ambiguity.

Some extra-linguistic factors must be considered too. When a term is to be transformed into another language and across culture the problem of communication arises in the absence of concept-toconcept correspondence between the SL and TL. That no established equivalents are frequently found in the $\mathrm{TL}$ is important in understanding all the linguistic and extra-linguistic factors. It is all the more essential for the transfer of inherent message from one language to another. This problem of one-to-one correspondence between the SL and the TL may be tackled in various ways depending on the nature of the text and the genius of the TL. In the case of some Bangla "new coinages" phenomenon of translation shift must be taken into account, keeping in mind that despite in terminology are a reflection of general convergence across linguistic and cultural barriers.

\section{Syntax : the feel of the text}

Lila Ray (1991 illustrated for Bangla the way syntax governs the feel of a text, from which to be is found what a writer does with his own language. She detailed this with several points like (a) Words (b)
Vocabularies (c) Sets of equivalence (d) Area of meaning (e) Words group that patterns sentence in English (f) Language level and (g) Style.

The last one is most abstract, for language is inseparable from style and also "style is the man (author) himself". Styles of languages in general also differ. English is kind of formal while literary Bangla tends to luxuriate in adjectives, euphemism and so on. Since style is language particular as well, style in TL is conditioned in manner in which a writer/translator utilizes available resources.

\subsection{The frame work}

If there is a new structure in course of dealing with a $2^{\text {nd }}$ language, that particular structure must be handled with a mechanism compatible with the grammatical vantage of both the languages. As a heuristic device a Bangla translator should concentrate on those English structures with which readers are less familiar. If the translator gets the feel of a sentence but does not know the mechanism of the structures, he is apt to face the problem of equivalence. If we assume that a Bangla translator as his background knowledge of SL/TL syntax is equipped with various grammatical aspects, then it must follow that he knows : some use of phrases and grammatical elements is meant for complementing relationship while some others for modifying. For Example ${ }^{3}$.

a. the woman (who) he was living together

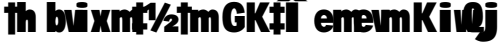

/je narir songe se eakotre bosobash korchilo/

"Who the woman- GEN to he was living together"

b. the man to discuss with

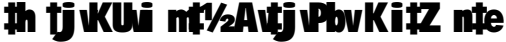

/je lok-Tar songe alochona korte hobe/

"Who the man GEN to discuss to do will-have"

c. the man who Tom has contact with 
th tj Kuli nt/2ligi thanthmate

/je lok-Tar songe tomer jogajog ache/

"who the man- GEN- with Tom-GEN contact has"

The finite and the infinite relative clauses have their correspondences in Bangla. Unlike in English, the relative pronoun cannot be deleted in Bangla sentence structure.

It also can be shown that while there can be more than one type of English construction, Bangla will have only one. (Example follows in the forth coming Sec 9. III)

In case of instances of divergent construction in English as against one in Bangla, structures concerned will be considered difficult for Bangla translator - since the question of selecting one particular from is involved. So, as a strategy in combating structural handling, the Bangla translator should better prefer Pied piping type construction $^{4}$, because it is close to Bangla structure. All he need to do is to note the change in the syntactic device when going from SL. to TL.

\subsection{Serial verbs}

The existence of two or more verbs in series in Bangla creates grave problem in translation in general. Occurrence of secondary elements called auxiliaries that follow the verb stem also poses problems in translation as these common auxiliaries do not always lend one and the same additional shade of meaning to all the stems with which they are used. For example,

'He got/ was seated' -- / tini boshe poRlen

区us etrncoij b

(back translation) ** He sat and fell.

\subsection{Pronouns and honorifics}

That most of the Bangla parts of speech (or inflected words) has definite usages with precise semantic there of, is frequently encountered by a translator. This is even more complicated in the case of pronouns and honorifics. Somewhat like Korean language Bangla has quite a number of grammatical items an account of which will show that in Bangla while gender of pronoun is definite until it the sentence, a pronoun is semantically (and socially) identified in grammatical category of $2^{\text {nd }}$ and $3^{\text {rd }}$ person. Moreover, the verb form must agree to the honorific-pronoun. Consider the uses like the following:-

\begin{tabular}{|c|c|c|c|c|}
\hline Avevo & I butk & $\mathrm{mex}^{\prime} \mathrm{Ku}$ & $f$ 好 $v$ & extrits \\
\hline$Z \times g$ & ZuK & extrov & & \\
\hline$Z 8$ & I \#k & $\begin{array}{l}\text { evorm } \\
\text { shattikar }\end{array}$ & bhalo & bashen \\
\hline tumi & take & basho & & \\
\hline tui & oke & bahish & & \\
\hline
\end{tabular}

\section{Ad positions}

(A cover-term for preposition in English and post-position in Bangla) The correct use of ad positions in translation is a desideratum, because they show the grammatical relation with sufficient clarity and distinctness. The difficulties faced by the translator are due to the existence of fewer adpositions in Bangla than English, mostly in cases of adpositions as part of verbs and adpositions as part of idiomatic expression where no equivalent of English ad position occurs in Bangla examples. < Please consider the forth coming examples.>

In this context Dr. Afzal Hossain mentioned (1985), the concept of translation shift (after Robberecht, 1982) in one way or another, 
which presupposes formal correspondence and content words as well.

Translation : "departures from formal correspondence in the process of going from SL to TL".

Transference : TL adposition may have the from and the value of meaning set up in the SL adposition : that is, it may have SL meaning.

English : $32^{\prime}$ by $6^{\prime}$ : Bangla : sholo phit bai bottrish phit (16 by 32 feet $=32^{\prime}$ by $16^{\prime}$ )

Here comes the question of the lack of congruity (Stochwell et al., 1965) which may be taken as true in the case of content words as in the case of function words. The fact is that : the semantic range of an adposition in Bangla is different from that of the item in SL English.

Since one language has a more highly differentiated codification than other, there arises the problem of discrimination in the language concerned. For various meanings of adposition of SL English, the complex problem of distribution of adposition arises.

Preposition of SL English is possibly the most perplexing grammatical phenomenon for a TL Bangla translator. (A general weakness of the Banglee learners of English as $2^{\text {nd }}$ language is that of positing appropriate preposition.) Several words used sometimes as adverbs and sometimes as preposition make it even more confusing for a Bangla translator. It may be shown that in certain context each occurrence of a particular item is translated by different Bangla equivalents, or only one Bangla equivalent is posited for a preposition used in different semantic shades.

\section{Divergence}

The forthcoming examples given in different sections may be studied in order to ascertain the divergent phenomena that place a Bangla translator into difficulty and indecision. And to come out of indecision a Bangla translator has to acquire ability to discriminate the subtle shades of meaning expressed by certain realtors in English. Please take a closer look into the following examples :

I. Use of grammatical items "from" translated into Bangla by one symbol/theke/.

a. From $1^{\text {st }}$ Apfil (non-perfect tense)

a. He did it from gratitude.

b. Light emanates from the sun

c. This is a quotation from Milton

d. His skill comes from practice

e. The income derived from the ownership of land is high.

f. Man is entirely different from other animal

g. He has retied from business

h. The patient is now free from danger

i. He advised us to desist from that attempt

II. Use of grammatical item "after" translated into Bangla by different Bangla equivalent ( Hossain, 1985)

\begin{tabular}{|c|c|c|}
\hline after dinner & wathti i CPi & [pore] \\
\hline after the thief & IPti i va axaQ & [pichu-pichu] \\
\hline after him & I i valb & [pechone] \\
\hline after Dr. Hossain & Wtruthabi Abyin $\#$ & [onushorone] \\
\hline after all that & GZne ntË & [shotteo] \\
\hline after Yeats. manne & Btaltini $\times 0$ & [dhonge] \\
\hline after his style & $I i \div \sqrt{B j}$ Ablynex & [onujai] \\
\hline
\end{tabular}

III. Different English items translated into Bangla by single item. 


$\begin{array}{ll}\text { English } & \text { Bangla } \\ \text { after } & \text { n㻥 } \\ \text { despite } & \text { [shotteo] } \\ \text { inspite of } & \end{array}$

IV. Equivalents of English items "about" in Bangla translation. We have placed English and plausible Bangla correspondences together. For plausible Bangla items for "about" phonemic forms are given as word-to word-glosses.

A. Close equivalents :

I was concerned about it.

Think about casting

I agree about one thing

B. Related equivalents :

Of course I don't mean

hanging about the set.

He replaced the cigar and looked about him.

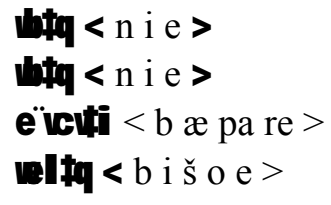

B. No ad positional equivalents : I dropped the key somewhere kothao $>$ about here.

Walking about the town is nice

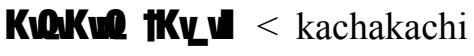

knti i Prinitk kni ga kni Ula

[shohorer] [charidike]

[shohormoye] [shohor tae]

C. No equivalents :

Books are lying about

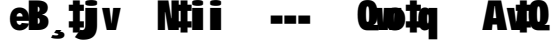

[boigulo gorer----cho Rie the room ache] "Books the room - scatter has"
There are many other related problems that have to be tackled by a Bangla translator when translating from English. Some of the mentionable ones are :-
A. Kinship terms
B. Diglossia
a. Semantic field - word to word translation - inferential translation
C. Semantic elaboration - freedom taken by TL
D. Linguistic equivalence - referential meaning.

Elaborations of these may be forwarded with great details, but they are likely to result in the lengthening of our discussion beyond the scope of this paper. In fact, real problems of a Bangla translator are most of the times situational or contextual, which are readily taken care of by the translator himself by his capability to find a solution may vary enormously. Levy stresses the intuitive element in translating saying "actual translation work is pragmatic" (Levy 969:150)

\section{Conclusion}

From the above discussion it should be clear by now that in translation theory, there is an essential hierarchy of semiotic aspects (as referred to in Sec. 2.0. and 3.1.1.1 earlier) or principles which applies to process of translation from source to target languages. It is marked by the dominance of the pragmatic principle over those of semantics and syntax. By the term "Pragmatic Principle" as it is used in both theory and practice of translation we should understand the demand of paying heed to contextual-communicative and receptive conditions in the process of translating. In order to produce the same communicative effect as intended by the original, this poses the translators problem. Particularly for literary-artistic translation for Bangla the structural properties of language itself are subject to the pragmatic principle. Because a piece of literary translation has to function as an original (a novel, drama, poem etc.- these are greater in number in Bangla translation) for the reading public without actually being the original.

\section{Other problems}


Thus, it follows that subjectivity and individual traits of an author find their expression in style and register. Hence stylistic forms and registeral features should also be considered as linguistic elements, because these necessitate a selective activity of the author/translator from a broad spectrum of linguistic variation.

Note:

1. Alexander Tytler's "Essay on the Principles of Translation" for example.

2. Folk-etymological examples are not considered here.

3. After Hossain, 1985. This may be noted that the first example is complementing relationship and the next two are for modifying .

4. Pied piping construction refers to to the type of sentences that bemuse the readers not by the structure of the sentence or patterns, but to the semantic charms evolving from the context or the story of the writer like the tales of "The Piper of Hamilon"

\section{References :}

Casagrande. J. 1954. "The ends of translation". International Journal of American Linguistic.

Catford. J.C. 1956. A Linguistic Theory of Translation : An Essay in Applied Linguistics, London : Oxford Unev. Press.

Garg. R.C. 1984. Problems of Equivalence in Literary Translation, Proceedings of First International Conference of "Literature in Translation”. New Delhi, India : J.N. University.

Hossain, Afzal. 1985. 'A study of English adpositions relevant to the needs of Bangla speaking learners', Ph.D dissertation (unpublished), University of Poona, India.

Huq. Daniul. M. 1990. Teaching English Pronunciation to Bangla L.I. Learners, Journal of the Institute of Modern Languages, Vol- , P-

Jakobson, R. 1959. Die literarische Ubersetzung. Theorie einer Kunstgattung, Trans : Walter Schamschula, Frankturt am Main : Athenaion.
J.W. 1965. The Grammatical Structures of English and Spanish, The Univ. of Chicago Press.

Levy, J. 1996. Die Literarische Ubersetyung: Theorie einer Kunstgattung, Trans: Walter Schomschula, Frankfurt am Main: Athenaion.

Levy, J. 2000. "Translation as a Decision Process" in Venute, L (ed.) The Translation Studies Reader. London: Routledge.

Nida. E. 1964. Towards a Science of Translating, E.J. Brill. Leiden.

--- and Taber. C. 1969. The Theory and Practice of Translation. Leiden: E.J. Brill.

Ray, Lila. 1976. "Multi-Dimension Translation : Poetry" in Translation : Application and Research, ed. Richard W. Brislin, New York : Garder Press. Inc.

--- 1953. "Kinship terms in translation" Proceedings of the First International Congerence on "Literature In Translation" J.N. Univ. India

--- 1991. Modern Bengali Poems. Calcutta: Paschimbanga Bangla Akademi.

Richards, I.A. 1953, Towards a theory of translation. "Studies in Chinese thought", American Anthropological Association. Vol. 55. University of Chicago Press.

Robbert. P. 1982. Linguisties and Translation, IRAL 20, No. 3

Sapir. Edward. 1956. Cultrure, Language and Personality, Barkley, Los Angeles : University of California Press.

Saussure, F.De 1974 Course in general Linguistics, London : Fontana. Stochurek. R.P.

Stochwell, R.P., Bower, J.D. and Martin, J.W. 1965. The Grammatica Structures of English and Spanish. The University of Chicago Press.

Email Contact : daniul79@hotmail.com. 